\title{
Laboratory Evaluation of Interactions in the Degradation of a Polypropylene Geotextile in Marine Environments
}

\author{
José Ricardo Carneiro $\left(\mathbb{D},{ }^{1}\right.$ Paulo Joaquim Almeida, ${ }^{2}$ and Maria de Lurdes Lopes ${ }^{1}$ \\ ${ }^{1}$ Construct-Geo, Faculty of Engineering, University of Porto, Rua Dr. Roberto Frias, 4200-465 Porto, Portugal \\ ${ }^{2}$ Requimte, Faculty of Sciences, University of Porto, Rua do Campo Alegre, 687, 4169-007 Porto, Portugal \\ Correspondence should be addressed to José Ricardo Carneiro; rcarneir@fe.up.pt
}

Received 13 December 2017; Revised 5 March 2018; Accepted 21 March 2018; Published 3 May 2018

Academic Editor: Jun Liu

Copyright (c) 2018 José Ricardo Carneiro et al. This is an open access article distributed under the Creative Commons Attribution License, which permits unrestricted use, distribution, and reproduction in any medium, provided the original work is properly cited.

The long-term behaviour of geosynthetics applied in coastal engineering structures can be adversely affected by many agents. This paper studies the resistance of a nonwoven polypropylene geotextile against some degradation agents present in marine environments and evaluates the existence of interactions between them. For that purpose, the geotextile was exposed to some laboratory degradation tests: immersion tests (in seawater, deionised water, and sodium chloride $35 \mathrm{~g} \cdot \mathrm{L}^{-1}$ ), thermooxidation, and artificial weathering. The geotextile was (1) exposed separately to each degradation test and (2) exposed successively to combinations of two or three degradation tests. The damage caused by the degradation tests was evaluated by monitoring the tensile properties of the geotextile. Based on the changes occurred in tensile strength, reduction factors were determined. The reduction factors obtained directly in the multiple exposures were compared with those obtained by the traditional methodology for the combined effect of the degradation agents. The results, among other findings, showed the existence of relevant interactions between the degradation agents and showed that the reduction factors obtained by the traditional methodology were unable to represent accurately (by underestimating) the degradation occurred in the geotextile.

\section{Introduction}

Geosynthetics are polymeric materials that can be used in the construction of many coastal engineering structures, such as breakwaters, dykes, groynes, seawalls, jetties, artificial reefs, or revetments $[1,2]$. The advantages of using these materials are the ease of installation (and future removal, if necessary), high versatility and efficiency, low cost, and low environmental impact. The functions of geosynthetics in coastal engineering structures include filtration, drainage, separation, reinforcement, containment, or erosion control $[1,2]$. The geotextiles (one of the main groups of geosynthetics) are typically used in coastal engineering structures as filters and for manufacturing sand-filled elements (called geosystems), like geobags, geotubes, or geocontainers. Pilarczyk [1] and Bezuijen and Vastenburg [2] provide an extensive description of the available knowledge about geosynthetics in coastal engineering.

In marine environments, the geosynthetics can be in contact with many degradation agents capable of causing unwanted changes in their properties, affecting their performance. The most common degradation agents in these environments include seawater, oxygen, solar radiation and other weathering agents, biological agents, and the action of waves, currents, and tides [3-5]. The geosynthetics may also suffer mechanical damage during the installation process, where in some cases they are subjected to higher stresses than during service [6].

Polypropylene (PP) (a polymer mostly used for the production of geotextiles) has a good resistance against many liquids (including seawater [7]) and biological degradation. However, its resistance against oxidation is substantially lower $[8,9]$. The oxidation process of PP follows a chain reaction mechanism formed by three main steps: initiation, propagation, and termination. The initiation step consists in the formation of free radicals (R•) (Reaction (1)) mainly by the action of temperature (thermooxidation) or by the action of ultraviolet (UV) radiation (photooxidation). The free radicals $\mathrm{R} \bullet$ promptly react with oxygen $\left(\mathrm{O}_{2}\right)$, forming peroxide radicals (ROO•) (Reaction (2)). The radicals $\mathrm{ROO} \bullet$ then extract hydrogen atoms from surrounding polymers, forming hydroperoxides $(\mathrm{ROOH})$ and 
more free radicals $\mathrm{R} \bullet($ Reaction $(3))$. The free radicals $\mathrm{R} \bullet$ can react again according to Reaction (2), propagating degradation. The hydroperoxides $\mathrm{ROOH}$ are very unstable, being easily converted into the free radicals $\mathrm{RO} \bullet$, $\mathrm{ROO} \bullet$, and $\bullet \mathrm{OH}$ (Reactions (4) and (5)), which can also extract hydrogen atoms from surrounding polymers and propagate degradation $[8-10]$.

$$
\begin{aligned}
& \mathrm{RH}(\text { polymer }) \\
& + \text { energy }\left(\frac{\text { Heat }}{\mathrm{UV} \text { radiation }}\right) \rightarrow \mathrm{R} \bullet \\
& \mathrm{R} \bullet+\mathrm{O}_{2} \longrightarrow \mathrm{ROO} \bullet \\
& \mathrm{ROO} \bullet+\mathrm{RH} \\
& \mathrm{ROOH}
\end{aligned}
$$

The oxidation process (autooxidative mechanism) will continue until all free radicals are transformed into nonreactive compounds (e.g., by reacting between them or by the action of chemical stabilisers) [8-10]. The occurrence of oxidation of PP products is practically unavoidable. However, in the absence of UV radiation, the oxidation process of $\mathrm{PP}$ is relatively slow at ambient temperatures (but cannot be neglected when considering products for long-term use) [11].

In many coastal engineering applications, the geosynthetics are only exposed to UV radiation during installation (usually a short period of time), being subsequently covered by sand, by other construction materials or by seawater. However, there are cases (like geobags, geotubes, or geocontainers used in groynes or breakwaters) where the geosynthetics can be exposed for longer periods of time. In addition, unpredictable UV exposure may also occur (e.g., due to the removal of sand by the action of the waves in buried structures) [7]. The damage caused by photooxidation (e.g., reduction in mechanical strength) can be retarded by adding chemical additives (like antioxidants or UV stabilisers) to the geosynthetics [9, 12-14].

The long-term behaviour of the geosynthetics is normally predicted based on data obtained from laboratory tests (degradation under accelerated conditions) [15-18]. In addition, their resistance against degradation can also be evaluated by field tests (degradation under natural conditions) $[5,7,14]$. The damage occurred in geotextiles during the degradation tests is often determined by monitoring changes in their tensile behaviour (in accordance with the recommendations of EN 12226 [19]). The changes occurred in other properties (puncture properties [5, 14], physical properties [7], or hydraulic properties [20]) and other techniques (like scanning electron microscopy $[13,14,21]$, infrared spectroscopy [22, 23], or liquid chromatography $[23,24])$ can also be used for damage evaluation.

When designing with geosynthetics, reduction factors (RFs) are often introduced to account for the degradation that occurs over time. Each reduction factor normally represents a decrease in resistance (known or estimated) due to the action of one, or more, degradation agent. For example, for reinforcement applications, the tensile strength $(T)$ of the geosynthetics is typically affected by a set of partial reduction factors accounting for the effects of installation damage $\left(\mathrm{RF}_{\mathrm{ID}}\right)$, creep $\left(\mathrm{RF}_{\mathrm{C}}\right)$, weathering $\left(\mathrm{RF}_{\mathrm{W}}\right)$, chemical and biological agents $\left(\mathrm{RF}_{\mathrm{CB}}\right)$, and a factor of safety $\left(f_{\mathrm{s}}\right)(6)[25,26]$. The use of (6) enables the determination of the design tensile strength $\left(T_{\mathrm{D}}\right)$ :

$$
T_{\mathrm{D}}=\frac{T}{\mathrm{RF}_{\mathrm{ID}} \times \mathrm{RF}_{\mathrm{C}} \times \mathrm{RF}_{\mathrm{W}} \times \mathrm{RF}_{\mathrm{CB}} \times f_{\mathrm{s}}} .
$$

The actual design methods, the standards available for degradation tests of geosynthetics (e.g., [15-18]), and most studies available in literature consider the isolated action of the degradation agents, not accounting for possible interactions between them. However, the combined effect of the degradation agents can be different (more severe) from the sum of their isolated actions [27-29]. For example, Carneiro et al. [27] showed the existence of interactions between chemical agents in the degradation of a PP geotextile. Interactions have also been found between mechanical degradation agents of geosynthetics [28-30]. The existence of such interactions can lead to inaccurate global reduction factors (used in the design), which are traditionally obtained by multiplying relevant partial reduction factors (each determined in isolation).

This work studies the resistance of a PP geotextile against some degradation agents present in marine environments. For that purpose, laboratory degradation tests were carried out to evaluate the resistance of the geotextile against seawater, thermooxidation, and weathering and to identify interactions between the previous agents. The main goals of the work included (1) determination of the effect of the degradation agents in the tensile properties of the geotextile, (2) identification of interactions between the degradation agents, and (3) comparison of the reduction factors obtained by the traditional methodology (determination of the reduction factors in isolation for each degradation agent and further multiplication) and by an alternative approach (successive exposure) for the combined effect of the degradation agents.

\section{Materials and Methods}

2.1. Geotextile. This work studied a nonwoven needlepunched geotextile made from PP fibres stabilised with $0.2 \%$ (percentage in weight) of the additive Chimassorb 944-a UV stabiliser belonging to the HALS (hindered amine light stabilisers) family. The PP fibres had a linear mass of 8 denier, a length of $75 \mathrm{~mm}$, and a diameter of about 30-40 $\mu \mathrm{m}$. The main physical, mechanical, and hydraulic properties of the geotextile can be found in Table 1 .

The sampling process (for the characterisation and degradation tests) was carried out according to EN ISO 9862 [37]). The specimens (machine direction of production) were collected from positions evenly distributed over the full width and length of the geotextile (supplied in a roll), but not closer than $100 \mathrm{~mm}$ to the edges. The specimens for the same 
TABLE 1: Main properties of the geotextile (undamaged sample).

\begin{tabular}{lcc}
\hline Property & Test standard & Geotextile \\
\hline Mass per unit area $\left(\mathrm{g} \cdot \mathrm{m}^{-2}\right)$ & EN ISO 9864 [31] & $502( \pm 25)$ \\
Thickness at $2 \mathrm{kPa}(\mathrm{mm})$ & EN ISO 9863-1 [32] & $3.81( \pm 0.08)$ \\
Tensile strength $\mathrm{MD}^{\mathrm{a}}\left(\mathrm{kN} \cdot \mathrm{m}^{-1}\right)$ & EN 29073-3 [33] & $26.64( \pm 1.41)$ \\
Elongation at the maximum load $\mathrm{MD}^{\mathrm{a}}(\%)$ & EN 29073-3 [33] & $71.6( \pm 3.2)$ \\
Tensile strength $\mathrm{CMD}^{\mathrm{b}}\left(\mathrm{kN} \cdot \mathrm{m}^{-1}\right)$ & EN 29073-3 [33] & $13.43( \pm 1.03)$ \\
Elongation at the maximum load CMD ${ }^{\mathrm{b}}(\%)$ & EN 29073-3 [33] & $122.9( \pm 6.2)$ \\
CBR puncture resistance $(\mathrm{kN})$ & EN ISO 12236 [34] & $2.69( \pm 0.15)$ \\
Permeability $\left(\mathrm{VI}_{\mathrm{H} 50}\right)^{\mathrm{c}}\left(\mathrm{mm} \cdot \mathrm{s}^{-1}\right)$ & EN ISO 11058 [35] & $39.7( \pm 5.0)$ \\
Pore size $\left(\mathrm{O}_{90}\right)^{\mathrm{d}}(\mu \mathrm{m})$ & EN ISO 12956 [36] & $66.0( \pm 4.9)$ \\
\hline
\end{tabular}

The $95 \%$ confidence intervals are given in parentheses; ${ }^{a} \mathrm{MD}$, machine direction of production; ${ }^{\mathrm{b}} \mathrm{CMD}$, cross-machine direction of production; ${ }^{\mathrm{c}} \mathrm{VI}_{\mathrm{H} 50}$, velocity index for a head loss of $50 \mathrm{~mm}$; ${ }^{\mathrm{d}} \mathrm{O}_{90}$, characteristic opening size.

characterisation or degradation tests (5 specimens for each test) were taken from different longitudinal and transverse positions of the roll. The specimens were $50 \mathrm{~mm}$ wide and $400 \mathrm{~mm}$ long (number and dimensions according to EN $12226[19])$.

2.2. Degradation Tests. First, the geotextile was exposed separately to some laboratory degradation tests (single exposure): immersions in liquids, thermooxidation, and artificial weathering (description of the tests in the following points). Then, the geotextile was exposed consecutively (multiple exposure) to some combinations of two or three of the previous degradation tests. Table 2 summarizes the degradation tests performed.

2.2.1. Immersion Tests. The geotextile was immersed, at room temperature (about $20^{\circ} \mathrm{C}$ ), in seawater (collected directly from the sea and used without any treatment), in deionised water $\left(\mathrm{H}_{2} \mathrm{O}\right)$, and in an aqueous solution of sodium chloride $(\mathrm{NaCl})$ (concentration of $35 \mathrm{~g} \cdot \mathrm{L}^{-1}$ ). The concentration of the solution of sodium chloride intended to simulate the amount of salts (mostly, but not entirely, sodium chloride) existent in seawater is typically $35 \mathrm{~g} \cdot \mathrm{L}^{-1}$. The immersion tests were carried out in the dark and had a duration of 12 months.

The specimens that were subsequently exposed to thermooxidation or artificial weathering (multiple exposures) were not washed after the immersion tests (in order to be contaminated with remains of the immersion solutions) and were dried at room temperature in the absence of light. The subsequent degradation tests were carried out in a short period of time (a few days or weeks) after the drying process.

2.2.2. Thermooxidation Tests. The thermooxidation tests consisted in exposing the geotextile at $110^{\circ} \mathrm{C}$ during 56 days. These tests were carried out in an oven (Heraeus Instruments, model T6120) with a normal oxygen atmosphere $\left(21 \%\right.$ of $\left.\mathrm{O}_{2}\right)$ and without forced air circulation. With exception for the higher exposure time, the thermooxidation tests were carried out according to method A of EN ISO 13438 [17]. According to this standard, the resistance of PP geotextiles against thermooxidation can be evaluated by exposing the materials at $110^{\circ} \mathrm{C}$ during 14 days (method
TABLe 2: Degradation tests performed.

\begin{tabular}{lc}
\hline Single exposure & Multiple exposures \\
\hline Immersion in seawater & Seawater + TO \\
Immersion in $\mathrm{H}_{2} \mathrm{O}$ & Seawater + QUV \\
Immersion in $\mathrm{NaCl}$ & $\mathrm{H}_{2} \mathrm{O}+\mathrm{TO}$ \\
Thermooxidation (TO) & $\mathrm{H}_{2} \mathrm{O}+\mathrm{QUV}$ \\
Artificial weathering (QUV) & $\mathrm{NaCl}+\mathrm{TO}$ \\
& $\mathrm{NaCl}+\mathrm{QUV}$ \\
& QUV + TO \\
& Seawater + QUV + TO \\
\hline
\end{tabular}

A1-for all applications, except reinforcement) or during 28 days (method A2-for reinforcement applications). The increase of the exposure time to 56 days was intended to harshen the degradation conditions and thereby enhance the effects of thermooxidation.

2.2.3. Artificial Weathering Tests. The artificial weathering tests (alternated exposure to UV radiation, water spray, and condensation) were performed in a laboratory weatherometer (Q-Panel Lab Products, model QUV/spray). The geotextile was exposed during 500 hours to the following weathering cycle:

Step 1: Exposure to UV radiation ( 6 hours, $60^{\circ} \mathrm{C}$ )

Step 2: Water spray (10 minutes, water at room temperature)

Step 3: Condensation (2 hours, $45^{\circ} \mathrm{C}$ )

(Return to Step 1)

The UV radiation was provided by fluorescent UV lamps (type UVA-340). The water spray (flow of $5 \mathrm{~L} \cdot \mathrm{min}^{-1}$ ) causes a fast decrease in temperature (from $60^{\circ} \mathrm{C}$ to about $24^{\circ} \mathrm{C}$ ) and can promote some surface erosion. The water used in the spray step was treated microbiologically and purified by reverse osmosis, followed by deionisation on ionic exchange columns. In the condensation step, the water (from the public supply network) existent in a reservoir located at the bottom of the weatherometer was heated to produce vapour that condensates (distilled water) at the surface of the exposed specimens. 
During the 500 test-hours, the geotextile was exposed to about 61 weathering cycles (each cycle had 8 hours and 10 minutes). The irradiance during the UV-exposure step (total duration of about 367 hours) was $0.68 \mathrm{~W} \cdot \mathrm{m}^{-2}$ at $340 \mathrm{~nm}$. The total UV radiant exposure (between 290 and $400 \mathrm{~nm}$ ) was $51.8 \mathrm{MJ} \cdot \mathrm{m}^{-2}$.

2.3. Evaluation of the Damage Suffered by the Geotextile. The damage suffered by the geotextile (during the degradation tests) was evaluated by tensile tests according to EN 29073-3 [33] (the method specified in EN 12226 [19] for determining the changes in the tensile properties of aged nonwoven geotextiles). These tests (velocity of $100 \mathrm{~mm} \cdot \mathrm{min}^{-1}$ ) were carried out in an equipment from Lloyd Instruments (model LR $50 \mathrm{~K}$ ) equipped with a load cell of $5 \mathrm{kN}$ (from Lloyd Instruments). Each tensile test included the analysis of 5 specimens (in the machine direction of production) with a length of $200 \mathrm{~mm}$ (between grips) and a width of $50 \mathrm{~mm}$.

The mechanical parameters obtained in the tensile tests included tensile strength ( $T$ in $\mathrm{kN} \cdot \mathrm{m}^{-1}$ ) and elongation at the maximum load $\left(E_{\mathrm{ML}}\right.$ in \%). Elongation was determined by expressing the relative displacement of the grips as a percentage of the original length $(200 \mathrm{~mm})$ (as specified in EN 29073-3 [33]). The results obtained for tensile strength and elongation at the maximum load are presented with $95 \%$ confidence intervals determined according to the following Montgomery and Runger [38] equation:

$$
\mu=x \pm t_{\alpha / 2, n-1} \frac{s}{\sqrt{n}}
$$

Where $\mu$ is the population mean, $x$ is the sample mean, $t$ is Student's $t$-distribution value for the confidence level $\alpha$ and $n-1$ degrees of freedom, $n$ is the number of specimens tested for each sample, and $s$ is the sample standard deviation. The changes occurred in tensile strength are also presented in terms of retained tensile strength $\left(T_{\text {residual }}\right.$ in \%), obtained in accordance with EN 12226 [19] by dividing the tensile strength of the samples exposed to the degradation tests $\left(T_{\text {damaged }}\right)$ by the tensile strength of unexposed samples $\left(T_{\text {reference }}\right)$ :

$$
T_{\text {residual }}=\frac{T_{\text {damaged }}}{T_{\text {reference }}} \times 100 .
$$

2.4. Determination of Reduction Factors. Reduction factors were determined based on the changes occurred (during the degradation tests) in the tensile strength of the geotextile. Each reduction factor represents a reduction in resistance provoked by the degradation tests (single or multiple exposures). The reduction factors were determined by the following equation:

$$
\mathrm{RF}=\frac{T_{\text {reference }}}{T_{\text {damaged }}},
$$

where $T_{\text {reference }}$ and $T_{\text {damaged }}$ correspond, respectively, to the tensile strength of the geotextile before and after the degradation tests.

\begin{tabular}{|c|c|c|c|c|}
\hline Degradation test & $T\left(\mathrm{kN} \cdot \mathrm{m}^{-1}\right)$ & $E_{\mathrm{ML}}(\%)$ & $\begin{array}{l}T_{\text {residual }} \\
\text { (\%) }\end{array}$ & $\mathrm{RF}$ \\
\hline $\begin{array}{l}\text { Reference } \\
\text { (unexposed) }\end{array}$ & $26.64( \pm 1.41)$ & $71.6( \pm 3.2)$ & - & - \\
\hline $\begin{array}{l}\text { Immersion in } \\
\text { seawater }\end{array}$ & $26.20( \pm 2.50)$ & $72.4( \pm 7.7)$ & 98.3 & 1.02 \\
\hline Immersion in $\mathrm{H}_{2} \mathrm{O}$ & $26.82( \pm 2.67)$ & $71.5( \pm 5.6)$ & 100.7 & 1.00 \\
\hline sion in $\mathrm{NaCl}$ & 25.66 & 75.3 & 96.3 & 1.04 \\
\hline Thermooxidation & $24.67( \pm 1.88)$ & $53.3( \pm 4.5)$ & 92.6 & 1.08 \\
\hline $\begin{array}{l}\text { Artificial } \\
\text { weathering }\end{array}$ & $12.42( \pm 1.85)$ & $34.4( \pm 2.3)$ & 46.6 & 2.14 \\
\hline
\end{tabular}

TABle 3: Tensile properties of the geotextile before and after the single exposure degradation tests.

The $95 \%$ confidence intervals are given in parentheses.

The reduction factors obtained by the traditional methodology for the combined effect of two (or more) degradation agents $\left(\mathrm{RF}_{\text {agents } \mathrm{A}+\mathrm{B} \text { trad }}\right)$ (agents denominated generically by " $\mathrm{A}$ " and " $\mathrm{B}$ ") were determined by multiplying the reductions factors obtained individually for each degradation agent $\left(\mathrm{RF}_{\text {agent } A}\right.$ and $\mathrm{RF}_{\text {agent } \mathrm{B}}$, resp.):

$$
\mathrm{RF}_{\text {agents } \mathrm{A}+\mathrm{B} \text { trad }}=\mathrm{RF}_{\text {agent A }} \times \mathrm{RF}_{\text {agent } \mathrm{B}} \text {. }
$$

The reduction factors determined in this work correspond to particular degradation conditions and cannot be generalized or applied directly in the design (their determination was intended for allowing a better analysis and understanding of the results). For being used in the design, the reduction factors must be analysed case by case, having into account the specific conditions of the constructions. Moreover, it is necessary to determine if the conditions imposed in the degradation tests effectively represent the expected field degradation conditions.

\section{Results and Discussion}

3.1. Exposure to One Degradation Test (Single Exposure). The immersion tests did not cause relevant changes in the tensile strength and elongation at the maximum load of the geotextile (Table 3). The minor variations observed in tensile strength (retained tensile strengths between 96.3\% and $100.7 \%$ ) and elongation at the maximum load may be attributed to the heterogeneity of the geotextile. Indeed, the nonwoven geotextiles typically have some heterogeneity (arising from their manufacturing process), which can be responsible for small differences between properties determined in consecutive repetitions of a characterisation test.

The tensile properties of the geotextile were significantly more affected by the thermooxidation and artificial weathering tests than by the immersion tests (Table 3). Despite the inexistence of a considerable reduction in tensile strength (retained tensile strength of $92.6 \%$ ), the exposure to thermooxidation led to a pronounced decrease in elongation at the maximum load (reduction from $71.6 \%$ to $53.3 \%$ ). The artificial weathering test caused even higher reductions in the tensile strength (retained tensile strength of 46.6\%) and elongation at the maximum load (reduction from $71.6 \%$ to $34.4 \%$ ) of the geotextile. 


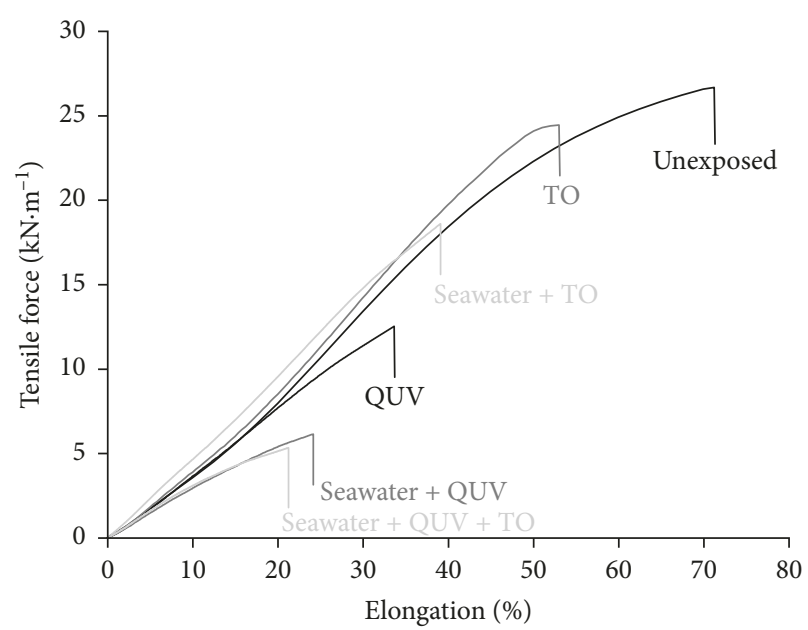

FIgURE 1: Mean curves "tensile force-elongation" obtained before and after the single and multiple exposure degradation tests.

The mean curves "tensile force-elongation" obtained for the geotextile before and after the thermooxidation and artificial weathering tests can be found in Figure 1. The analysis of those curves showed that, besides the changes in tensile strength and elongation at the maximum load, the exposure to thermooxidation also led to an increase in the stiffness of the geotextile. This increase in stiffness (and the reduction in elongation at the maximum load) may be related with the occurrence of some shrinkage (about 2.5\%) in the geotextile during the exposure to thermooxidation, which caused a decrease in the deformability of the nonwoven structure. Contrarily to the thermooxidation test, the exposure to artificial weathering did not cause an increase in the stiffness of the geotextile (at lower elongations, the mean curves "tensile force-elongation" were practically coincident before and after artificial weathering). It is worthy to mention that the mean curves "tensile force-elongation" obtained after the immersion tests were omitted from Figure 1 for simplification purposes (those curves were much coincident with the curve presented for the unexposed sample, confirming the inexistence of relevant changes in the tensile behaviour of the geotextile).

The PP geotextile presented a good resistance against the effects of seawater and hydrolysis. The damage occurred during the artificial weathering tests (considerable deterioration of the tensile properties of the geotextile) can be mainly attributed to the effects of UV radiation (it is well known that UV radiation is one of the main degradation agents of PP products). The presence of a small amount of the HALS-type UV stabiliser (only $0.2 \%$, percentage in weight) resulted in a substantial increase of the resistance of the PP geotextile against the effects of thermooxidation and UV radiation. Indeed, in the absence of the additive, the geotextile would be totally destructed (tensile strength reduced to zero) after the thermooxidation and artificial weathering tests [11].

\subsection{Exposure to Consecutive Degradation Tests (Multiple Exposures)}

3.2.1. Immersion Tests Followed by Thermooxidation. The successive exposure to seawater and thermooxidation (two
TABle 4: Tensile properties of the geotextile after the multiple exposure degradation tests.

\begin{tabular}{lcccc}
\hline Degradation test & $T\left(\mathrm{kN} \cdot \mathrm{m}^{-1}\right)$ & $E_{\mathrm{ML}}(\%)$ & $\begin{array}{c}T_{\text {residual }} \\
(\%)\end{array}$ & $\mathrm{RF}$ \\
\hline Seawater + TO & $18.56( \pm 2.35)$ & $39.1( \pm 5.5)$ & 69.7 & 1.44 \\
$\mathrm{H}_{2} \mathrm{O}+\mathrm{TO}$ & $25.01( \pm 2.27)$ & $54.2( \pm 4.6)$ & 93.9 & 1.07 \\
$\mathrm{NaCl}+\mathrm{TO}$ & $15.51( \pm 2.58)$ & $34.2( \pm 8.1)$ & 58.2 & 1.72 \\
$\mathrm{Seawater}+\mathrm{QUV}$ & $6.26( \pm 2.68)$ & $24.0( \pm 3.7)$ & 23.5 & 4.26 \\
$\mathrm{H}_{2} \mathrm{O}+\mathrm{QUV}$ & $12.31( \pm 1.43)$ & $34.5( \pm 2.1)$ & 46.2 & 2.16 \\
$\mathrm{NaCl}+\mathrm{QUV}$ & $10.12( \pm 2.32)$ & $30.4( \pm 4.1)$ & 38.0 & 2.63 \\
$\mathrm{QUV}+\mathrm{TO}$ & $12.30( \pm 1.19)$ & $31.9( \pm 2.6)$ & 46.2 & 2.17 \\
Seawater + QUV + TO & $5.39( \pm 1.60)$ & $21.2( \pm 4.1)$ & 20.2 & 4.94 \\
\hline
\end{tabular}

The $95 \%$ confidence intervals are given in parentheses.

agents that individually did not cause much relevant changes in the tensile strength of the geotextile) caused a decrease in tensile strength (reduction of 30.3\%) (Table 4). In addition, a decrease also occurred in elongation at the maximum load (reduction higher than that observed after the single exposure to thermooxidation). The mean curve "tensile force-elongation" obtained after the successive exposure to seawater and thermooxidation can be seen in Figure 1. Besides the changes in the tensile properties reported above, an increase in stiffness was also observed (like before, the occurrence of some shrinkage in the geotextile during the thermooxidation test may have contributed for this increase).

The deterioration of tensile strength in the successive exposure to seawater and thermooxidation shows that two agents that individually did not cause relevant damage to the geotextile (retained tensile strengths of $98.3 \%$ and $92.6 \%$, resp., after the single exposure degradation tests), together led to some degradation. Therefore, the interactions that may occur between the different degradation agents must not be neglected when accessing the durability of geotextiles.

The reduction observed in tensile strength may have some possible explanations: (1) the remains of seawater accelerated the oxidation process, (2) occurrence of losses of the HALS-type UV stabiliser during the immersion in seawater, leaving the geotextile less protected against oxidation (as previously mentioned, the oxidative resistance of PP geotextiles can be highly enhanced by the presence of Chimassorb 944 [11]), and (3) the remains of seawater could have prevented the HALS-type UV stabiliser from performing efficiently its protective function against thermooxidation. In order to try to explain the reduction in tensile strength observed after the successive exposure to seawater and thermooxidation, two other combinations of degradation tests were performed: (1) immersion in deionised water followed by thermooxidation and (2) immersion in sodium chloride $35 \mathrm{~g} \cdot \mathrm{L}^{-1}$ followed by thermooxidation.

The tensile strength (after the thermooxidation tests) of the sample previously immersed in water was similar to the tensile strength of the sample without immersion (retained tensile strengths of $93.9 \%$ and $92.6 \%$, resp.) (Table 4). Similarly to tensile strength, elongation at the maximum load also had no relevant differences $(54.2 \%$ and $53.3 \%$, resp.). Moreover, the mean curve "tensile force-elongation" obtained after the successive exposure to water and thermooxidation was much coincident with the curve presented 
in Figure 1 for the single exposure to thermooxidation. This way, the thermooxidative resistance of the geotextile was not affected by the previous immersion in water.

Contrarily to what happened with water, the immersion in sodium chloride $35 \mathrm{~g} \cdot \mathrm{L}^{-1}$ led to a reduction of the resistance of the geotextile against thermooxidation (Table 4). Indeed, the successive immersion in sodium chloride $35 \mathrm{~g} \cdot \mathrm{L}^{-1}$ and thermooxidation provoked relevant decreases in the tensile strength (retained tensile strength of 58.2\%) and elongation at the maximum load (from $71.6 \%$ to $34.2 \%$ ) of the geotextile. The reduction occurred in tensile strength was even more pronounced than that observed in the successive exposure to seawater and thermooxidation (reductions of $41.8 \%$ and $30.3 \%$, resp.). The sample previously immersed in sodium chloride $35 \mathrm{~g} \cdot \mathrm{L}^{-1}$ also suffered an increase in stiffness after the thermooxidation tests. With the obvious differences due to lower tensile strength and elongation at the maximum load, the mean curve "tensile force-elongation" obtained after the successive immersion in sodium chloride $35 \mathrm{~g} \cdot \mathrm{L}^{-1}$ and thermooxidation was relatively similar to the curve obtained after the multiple exposure to seawater and thermooxidation and therefore is not presented in Figure 1.

The only difference between the solution of sodium chloride $35 \mathrm{~g} \cdot \mathrm{L}^{-1}$ and water was the presence, or not, of the salt. This way, and having into account that the immersion in water did not cause a decrease in the resistance of the geotextile against thermooxidation, the damage occurred after the successive immersion in sodium chloride $35 \mathrm{~g} \cdot \mathrm{L}^{-1}$ and thermooxidation can only be ascribed to the presence of sodium chloride. It is worthy to remember that the concentration of sodium chloride was intended to simulate the typical amount of salts (mostly sodium chloride) existent in seawater.

Within the previous hypotheses for explaining the reduction of the thermooxidative resistance of the geotextile caused by seawater, the influence of sodium chloride in the oxidation process (probably by acting as a catalyst) is the most probable one. The inexistence of any interaction between water and thermooxidation helps to support that sodium chloride had a relevant role in the degradation occurred in the multiple exposures to (1) seawater and thermooxidation and (2) sodium chloride $35 \mathrm{~g} \cdot \mathrm{L}^{-1}$ and thermooxidation.

The occurrence of significant losses of the HALS-type UV stabiliser during the immersion in sodium chloride $35 \mathrm{~g} \cdot \mathrm{L}^{-1}$ and seawater is unlikely. Indeed, there were no evidences of losses of the additive in the immersion in water (the geotextile had a good resistance against the multiple exposure to water and thermooxidation), and there are no reasons to presume that the additional presence of sodium chloride (and other salts in the case of seawater) could have promoted such losses.

Regarding the third hypothesis, no information was found in literature about the possible interaction between sodium chloride and the HALS-type UV stabiliser. The results obtained in this work indicate that sodium chloride had some influence in the thermooxidative degradation of the geotextile. However, further studies are needed to undoubtedly clarify the reasons for the interactions found in the multiple exposures to (1) seawater and thermooxidation and (2) sodium chloride $35 \mathrm{~g} \cdot \mathrm{L}^{-1}$ and thermooxidation. These studies are mainly related with polymer chemistry, falling outside the area of civil engineering.

\subsubsection{Immersion Tests Followed by Artificial Weathering.}

The successive immersion in seawater and artificial weathering caused a considerable decrease in the tensile strength of the geotextile (reduction of 76.5\%) (Table 4). This decrease was higher than the decrease that occurred after the single exposure to artificial weathering (reduction of $53.4 \%$ ). The elongation at the maximum load (after the artificial weathering tests) was also lower for the sample previously immersed in seawater than for the sample without immersion (reductions from $71.6 \%$ to $24.0 \%$ and $34.4 \%$, resp.). When compared with the unexposed sample or with the sample exposed uniquely to artificial weathering, the stiffness of the geotextile suffered a relevant decrease for elongations higher than 5\% (Figure 1).

Having into account that the immersion in seawater (single exposure) had no relevant influence in the tensile properties of the geotextile, the degradation occurred in the multiple exposure to seawater and artificial weathering was higher than the sum of the individual effects of both single exposures. This way, and similarly to what happened with thermooxidation, an interaction also occurred between seawater and artificial weathering.

The hypotheses for explaining the interaction found between seawater and artificial weathering are the same as previously mentioned for the interaction observed between seawater and thermooxidation. As before, two more combinations of degradation tests were considered: (1) immersion in water followed by artificial weathering and (2) immersion in sodium chloride $35 \mathrm{~g} \cdot \mathrm{L}^{-1}$ followed by artificial weathering.

The immersion in water did not provoke a reduction of the weathering resistance of the geotextile (Table 4). Indeed, the sample previously immersed in water and the sample without immersion (exposed only to artificial weathering) had similar tensile properties after artificial weathering (retained tensile strengths of $46.2 \%$ and $46.6 \%$, resp.). Moreover, the mean curve "tensile force-elongation" obtained after the successive exposure to water and artificial weathering was practically coincident with the curve obtained after the single exposure to artificial weathering (presented in Figure 1). Therefore, as the resistance against thermooxidation, the weathering resistance of the geotextile was not affected by the previous immersion in water.

Similarly to what happened when combined with thermooxidation, the immersion in sodium chloride $35 \mathrm{~g} \cdot \mathrm{L}^{-1}$ also led to a reduction of the resistance of the geotextile against artificial weathering (Table 4). However, the reduction occurred in tensile strength after the successive exposure to sodium chloride $35 \mathrm{~g} \cdot \mathrm{L}^{-1}$, and artificial weathering (decrease of $62.0 \%$ ) was significantly lower than the reduction observed after the successive exposure to seawater and artificial weathering (reduction of $76.5 \%$ ). 
Despite being a lower reduction, this indicates the existence of some effect of sodium chloride in the degradation process of the geotextile by artificial weathering.

The main degradation mechanism during artificial weathering was photooxidation and, as for thermooxidation, the influence of sodium chloride in the oxidative process (by acting as a catalyst) is the most likely hypothesis for explaining the higher degradation of the geotextile. The occurrence of significant losses of the HALS-type UV stabiliser during the immersion tests is unlikely (as discussed before in Section 3.2.1), and no data were found in the literature about possible interactions between sodium chloride and Chimassorb 944. Like for the interactions with thermooxidation, additional studies (mainly related with polymer chemistry) are needed to explain the effect of sodium chloride in the weathering process of the geotextile.

\subsubsection{Artificial Weathering Followed by Thermooxidation.} The multiple exposure to artificial weathering and thermooxidation induced a decrease in tensile strength identical to the single exposure to artificial weathering (retained tensile strengths of $46.2 \%$ and $46.6 \%$, resp.) (Table 4 ). Similarly to what happened for tensile strength, there were also no relevant differences in elongation at the maximum load $(31.9 \%$ and $34.4 \%$, resp.). In addition, the mean curves "tensile force-elongation" obtained after the multiple exposure to artificial weathering and thermooxidation and after the single exposure to artificial weathering were almost coincident (for simplification purposes, the curve obtained after the multiple exposure is not represented in Figure 1). This showed that the subsequent thermooxidation test (after artificial weathering) did not cause additional damage to the geotextile (no interaction was found between artificial weathering and thermooxidation).

3.2.4. Successive Exposure to Seawater, Artificial Weathering, and Thermooxidation. The successive exposure to seawater, artificial weathering, and thermooxidation provoked the most pronounced changes in the tensile properties of the geotextile (reduction of $79.2 \%$ in tensile strength and reduction of elongation at the maximum load from $71.6 \%$ to $21.2 \%$ ) (Table 4), showing the existence of extensive damage in the nonwoven structure. With the difference due to lower tensile strength and elongation at the maximum load, the mean curve "tensile force-elongation" obtained after the multiple exposure to seawater, artificial weathering, and thermooxidation was relatively similar to the curve obtained after the multiple exposure to seawater and artificial weathering (no relevant changes were found in stiffness for elongations up to about 20\%) (Figure 1). When compared to the single exposures to seawater, artificial weathering, and thermooxidation, the stiffness of the geotextile suffered a considerable decrease for elongations higher than about $5 \%$.

The presence of the additional thermooxidation test (when compared to the multiple exposure to seawater and artificial weathering) resulted in a slightly higher deterioration of the tensile properties of the geotextile. Since no interactions were found between artificial weathering and

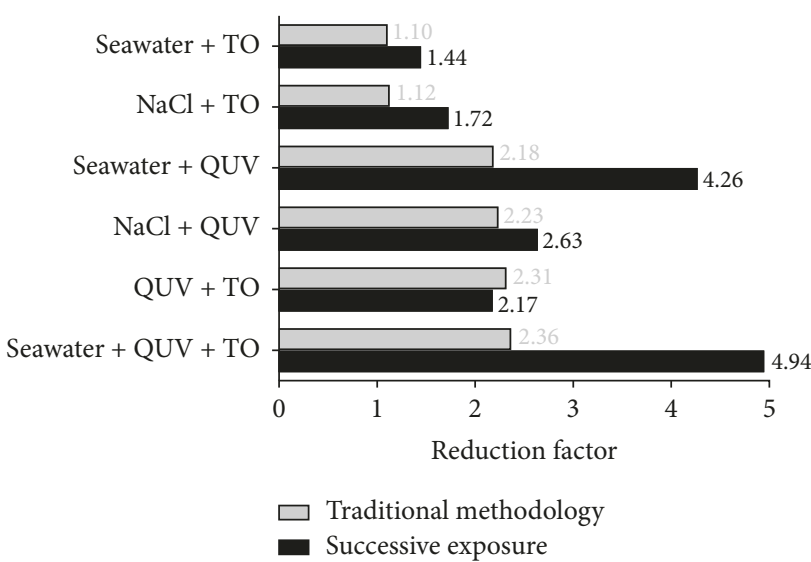

Figure 2: Comparison of the reduction factors obtained by the traditional methodology and by the successive exposure to the degradation agents.

thermooxidation (Section 3.2.3), the further deterioration of the geotextile may be due to traces of sodium chloride (from seawater) that could still be present after the multiple exposure to seawater and artificial weathering (Section 3.2.1 showed the existence of an interaction between sodium chloride and thermooxidation; the possible reasons for such interaction have already been discussed before).

3.3. Reduction Factors. The reduction factors obtained in the successive exposures to two or three degradation agents were compared with the reduction factors determined by the traditional methodology for the combined effect of those agents (determination of reduction factors in separate for each agent and further multiplication) (Figure 2). The reduction factors obtained directly from the single and multiple exposures carried out in this work can be found in Tables 3 and 4, respectively.

The reduction factor determined by the traditional methodology for the combined effect of artificial weathering and thermooxidation was similar (slightly higher) to that obtained in the successive exposure to both degradation agents (reduction factors of 2.31 and 2.17, resp.) (Figure 2). In this case, the traditional methodology provided a good approach to estimate the deterioration occurred in the tensile strength of the geotextile due to the combined effect of artificial weathering and thermooxidation (it is worthy to remember that no interaction was found between these degradation agents).

The reduction factors obtained in the successive exposures to (1) immersion in seawater and thermooxidation, (2) immersion in sodium chloride $35 \mathrm{~g} \cdot \mathrm{L}^{-1}$ and thermooxidation, (3) immersion in seawater and artificial weathering, and (4) immersion in sodium chloride $35 \mathrm{~g} \cdot \mathrm{L}^{-1}$ and artificial weathering were higher than those obtained by the traditional methodology for the combined effect of those degradation agents (Figure 2). For example, the reduction factor obtained in the successive immersion in seawater and artificial weathering (4.26) was about 2-times higher than the reduction factor (2.18) determined by multiplying the 
reduction factors obtained in the single exposures to seawater and to artificial weathering (1.02 and 2.14, resp.). The previous results indicate that the reduction factors provided by the traditional methodology were unable to represent correctly (by underestimating) the combined effect of the degradation agents. The differences found between the reduction factors (determined by the traditional methodology or obtained directly in the successive exposure to the degradation agents) can be explained by the interactions occurred between the degradation agents (which the traditional methodology is not being able to account for).

Similarly to the previous combinations of two degradation agents, the reduction factor obtained by the traditional methodology for the combined effect of three degradation agents (seawater, artificial weathering, and thermooxidation) was much lower (less than half) than the reduction factor obtained in the successive exposure to the agents (reduction factors of 2.36 and 4.94, resp.) (Figure 2). Once again, the reduction factors obtained by the traditional methodology underestimated the degradation caused by the combined effect of the degradation agents.

The reduction factors determined by the traditional methodology were lower than those obtained directly in the successive exposures to the degradation agents (exception for the combined effect of artificial weathering and thermooxidation, where no interactions were found between the agents). This showed that the multiplication of the reduction factors (each representing the isolated effect of a degradation agent) may not represent with accuracy the combined effect of the agents.

\section{Conclusions}

The damage (deterioration of tensile properties) suffered by a nonwoven PP geotextile in the successive exposure to degradation agents present in marine environments tended to be much different (higher) from the sum of the individual effects of those agents, showing the existence of interactions between them. Relevant interactions were found between (1) immersion in seawater and thermooxidation, (2) immersion in sodium chloride $35 \mathrm{~g} \cdot \mathrm{L}^{-1}$ and thermooxidation, (3) immersion in seawater and artificial weathering, (4) immersion in sodium chloride $35 \mathrm{~g} \cdot \mathrm{L}^{-1}$ and artificial weathering, and (5) immersion in seawater followed by artificial weathering and then by thermooxidation.

Some hypotheses have been advanced for trying to explain the interactions found between the degradation agents. The results showed that sodium chloride had a key influence in the thermo- or photooxidative process of the geotextile, probably by acting as a catalyst. However, further studies (mainly related with polymer chemistry) are needed to undoubtedly clarify the reasons for the interactions found in this work.

The identification and quantification of interactions between the different degradation agents is important to understand and predict the behaviour of the geotextiles under real conditions (where the agents rarely act in isolation). Recognizing such interactions can help understanding the degradation process of the materials and

may enable the development of strategies for enhancing their durability and improving their performance.

The reduction factors obtained directly in the multiple exposures to the degradation agents tended to be different from those calculated by the traditional methodology (determination of reduction factors in separate for each agent and further multiplication) for the combined effect of those agents. The traditional methodology was unable to represent accurately (underestimating) the damage caused by the combined effect of the degradation agents, being incapable of accounting for the interactions occurred between the agents. The most relevant examples of this occurred (1) in the successive immersion in seawater and artificial weathering and (2) in the successive immersion in seawater, followed by artificial weathering and then by thermooxidation. In both cases, the reduction factors obtained by the traditional methodology were much lower (about half) than those obtained directly in the successive exposures to the degradation agents.

The definition of reliable reduction factors (having into consideration the interactions that may occur between the degradation agents) can contribute for a better application of geosynthetics. Indeed, the definition of accurate reduction factors allows a better design and provides a higher guarantee of durability.

Finally, it is worthy to remember that the reduction factors presented in this work correspond to particular degradation conditions and cannot be generalized or applied directly in the design. No studies were carried out in order to find the relation between field conditions and the degradation conditions imposed to the geotextile.

\section{Abbreviations and symbols}

$\alpha:$

CMD:

$E_{\mathrm{ML}}$ :

$f_{\mathrm{s}}$ :

HALS:

MD:

$n:$

$\mathrm{O}_{90}:$

PP:

RF:

$\mathrm{RF}_{\text {agent A: }}$ :

$\mathrm{RF}_{\text {agent } \mathrm{B}}$ :

$\mathrm{RF}_{\text {agents } \mathrm{A}+\mathrm{B} \text { trad }}$ :

$\mathrm{RF}_{\mathrm{C}}$ :

$\mathrm{RF}_{\mathrm{CB}}$ :

$\mathrm{RF}_{\mathrm{ID}}$ :

$\mathrm{RF}_{\mathrm{W}}$ :

$s:$

$t:$

$T:$

$T_{\mathrm{D}}$ :

$T_{\text {damaged }}$ :

$T_{\text {reference }}$ :
Confidence level

Cross-machine direction of production

Elongation at the maximum load

Factor of safety

Hindered amine light stabiliser

Machine direction of production

Number of specimens

Characteristic opening size

Polypropylene

Reduction factor

Reduction factor for agent A

Reduction factor for agent $\mathrm{B}$

Reduction factor for the combined effect of agents A and B (traditional methodology)

Reduction factor for creep

Reduction factor for chemical and biological agents

Reduction factor for installation damage

Reduction factor for weathering

Sample standard deviation

Student's $t$-distribution value

Tensile strength

Design tensile strength

Tensile strength of exposed samples Tensile strength of reference samples (unexposed) 


$\begin{array}{ll}T_{\text {residual }}: & \text { Retained tensile strength } \\ \text { TO: } & \text { Thermooxidation } \\ \mu: & \text { Population mean } \\ \mathrm{UV}: & \text { Ultraviolet } \\ \mathrm{VI}_{\mathrm{H} 50}: & \text { Velocity index for a head loss of } 50 \mathrm{~mm} \\ x: & \text { Sample mean. }\end{array}$

\section{Conflicts of Interest}

The authors declare that they have no conflicts of interest.

\section{Acknowledgments}

The authors would like to thank "Carvalhos Lda." (Lousã, Portugal) for supplying the geotextile studied in this work. This work was financially supported by the Project POCI-010145-FEDER-007457, funded by FEDER funds through COMPETE 2020_ "Programa Operacional Competitividade e Internacionalização" (POCI) and by national funds through "FCT-Fundação para a Ciência e a Tecnologia". José Ricardo Carneiro would also like to thank FCT for the research grant SFRH/BPD/88730/2012 (grant supported by $\mathrm{POPH} / \mathrm{POCH} / \mathrm{FSE}$ funding).

\section{References}

[1] K. W. Pilarczyk, Geosynthetics and Geosystems in Hydraulic and Coastal Engineering, A.A. Balkema, Rotterdam, Netherlands, 1st edition, 2000.

[2] A. Bezuijen and E. W. Vastenburg, Geosystems: Design Rules and Applications, CRC Press/Balkema, Leiden, Netherlands, 1st edition, 2013.

[3] T. S. Ingold, The Geotextiles and Geomembranes Manual, Elsevier Advanced Technology, Oxford, UK, 1st edition, 1994.

[4] R. M. Koerner, Designing with Geosynthetics, Prentice-Hall, Upper Saddle River, NJ, USA, 1999.

[5] C. Hsieh, J.-B. Wang, and Y. F. Chiu, "Weathering properties of geotextiles in ocean environments," Geosynthetics International, vol. 13, no. 5, pp. 210-217, 2006.

[6] S. K. Shukla and J.-H. Yin, Fundamentals of Geosynthetics Engineering, Taylor \& Francis/Balkema, Leiden, Netherlands, 2006.

[7] J. R. Carneiro, M. Morais, and M. L. Lopes, "Degradation of polypropylene geotextiles with different chemical stabilisations in marine environments," Construction and Building Materials, vol. 165, pp. 877-886, 2018.

[8] C. Maier and T. Calafut, Polypropylene-the Definitive User's Guide and Databook, Plastic Design Library, New York, NY, USA, 1998.

[9] D. Feldman, "Polymer weathering: photo-oxidation," Journal of Polymers and the Environment, vol. 10, no. 4, pp. 163-173, 2002.

[10] J. H. Greenwood, H. F. Schroeder, and W. Voskamp, Durability of Geosynthetics, CRC Press, Boca Raton, FL, USA, 2nd edition, 2016.

[11] J. R. Carneiro, Durability of Geosynthetics in Environmental Structures - the Importance of Chemical Additives, Ph.D. thesis in Environmental Engineering, University of Porto, Porto, Portugal, 2009, in Portuguese.

[12] L. D. Suits and Y. G. Hsuan, "Assessing the photo-degradation of geosynthetics by outdoor exposure and laboratory weatherometer," Geotextiles and Geomembranes, vol. 21, no. 2, pp. 111-122, 2003.

[13] J. R. Carneiro, P. J. Almeida, and M. L. Lopes, "Accelerated weathering of polypropylene geotextiles," Science and Engineering of Composite Materials, vol. 18, no. 4, pp. 241-245, 2011.

[14] J. R. Carneiro and M. L. Lopes, "Natural weathering of polypropylene geotextiles treated with different chemical stabilisers," Geosynthetics International, vol. 24, no. 6, pp. 544-553, 2017.

[15] EN 14030, Geotextiles and Geotextile-Related ProductsScreening Test Method for Determining the Resistance to Acid and Alkaline Liquids, European Committee for Standardization, Brussels, Belgium, 2001.

[16] EN 12447, Geotextiles and Geotextile-Related ProductsScreening Test Method for Determining the Resistance to Hydrolysis in Water, European Committee for Standardization, Brussels, Belgium, 2001.

[17] EN ISO 13438, Geotextiles and Geotextile-Related ProductsScreening Test Method for Determining the Resistance to Oxidation, European Committee for Standardization, Brussels, Belgium, 2004.

[18] EN 12224, Geotextiles and Geotextile-Related ProductsDetermination of the Resistance to Weathering, European Committee for Standardization, Brussels, Belgium, 2000.

[19] EN 12226, Geosynthetics-General Tests for Evaluation following Durability Testing, European Committee for Standardization, Brussels, Belgium, 2012.

[20] S. P. Moreira, J. R. Carneiro, and M. L. Lopes, "Effect of natural weathering on the water permeability behaviour of nonwoven polypropylene geotextiles," in Proceedings of the 9th International Conference on Geosynthetics, vol. 2, pp. 829-832, Guarujá, Brazil, May 2010.

[21] J. R. Carneiro, P. J. Almeida, and M. L. Lopes, "Durability of polypropylene geotextiles exposed to artificial weathering conditions," in Proceedings of the 5th International Congress on Environmental Geotechnics, vol. 1, pp. 399-406, Cardiff, UK, 2006.

[22] X. Yang and X. Ding, "Prediction of outdoor weathering performance of polypropylene filaments by accelerated weathering tests," Geotextiles and Geomembranes, vol. 24, no. 2, pp. 103-109, 2006.

[23] I. M. Valente, J. R. Carneiro, P. J. Almeida, and M. L. Lopes, "Chemical studies about the durability of polypropylene geotextiles," in Proceedings of the 9th International Conference on Geosynthetics, vol. 2, pp. 785-788, Guarujá, Brazil, May 2010.

[24] I. M. Valente, J. R. Carneiro, P. J. Almeida, and M. L. Lopes, "Determination of Chimassorb 944 in polypropylene geotextiles by HPLC-UV," Analytical Letters, vol. 44, no. 4, pp. 617-625, 2011.

[25] ISO/TR 20432, Guidelines for the Determination of the Long-Term Strength of Geosynthetics for Soil Reinforcement, International Organization for Standardization, Geneva, Switzerland, 2007.

[26] D. M. Carlos, J. R. Carneiro, M. Pinho-Lopes, and M. L. Lopes, "Effect of soil grain size distribution on the mechanical damage of nonwoven geotextiles under repeated loading," International Journal of Geosynthetics and Ground Engineering, vol. 1, no. 1, p. 7, 2015.

[27] J. R. Carneiro, P. J. Almeida, and M. L. Lopes, "Some synergisms in the laboratory degradation of a polypropylene geotextile," Construction and Building Materials, vol. 73, pp. 586-591, 2014. 
[28] J. R. Carneiro and M. L. Lopes, "Resistance of nonwoven geotextiles against mechanical damage under repeated loading and abrasion," in Proceedings of the 6th European Geosynthetics Congress, pp. 875-883, Ljubljana, Slovenia, September 2016.

[29] M. Dias, J. R. Carneiro, and M. L. Lopes, "Resistance of a nonwoven geotextile against mechanical damage and abrasion," Ciência e Tecnologia dos Materiais, vol. 29, no. 1, pp. 177-181, 2017.

[30] A. Rosete, P. M. Lopes, M. Pinho-Lopes, and M. L. Lopes, "Tensile and hydraulic properties of geosynthetics after mechanical damage and abrasion laboratory tests," Geosynthetics International, vol. 20, no. 5, pp. 358-374, 2013.

[31] EN ISO 9864, Geosynthetics-Test Method for the Determination of Mass per Unit Area of Geotextiles and Geotextile-Related Products, European Committee for Standardization, Brussels, Belgium, 2005.

[32] EN ISO 9863-1, Geosynthetics-Determination of Thickness at Specified Pressures, Part 1: Single Layers, European Committee for Standardization, Brussels, Belgium, 2005.

[33] EN 29073-3, Textiles-Test Methods for Nonwovens, Part 3: Determination of Tensile Strength and Elongation, European Committee for Standardization, Brussels, Belgium, 1992.

[34] EN ISO 12236, Geosynthetics-Static Puncture Test (CBR Test), European Committee for Standardization, Brussels, Belgium, 2006.

[35] EN ISO 11058, Geotextiles and Geotextile Related Products-Determination of Water Permeability Characteristics Normal to the Plane, without Load, European Committee for Standardization, Brussels, Belgium, 2010.

[36] EN ISO 12956, Geotextiles and Geotextile Related Products-Determination of the Characteristic Opening Size, European Committee for Standardization, Brussels, Belgium, 2010.

[37] EN ISO 9862, Geosynthetics-Sampling and Preparation of Test Specimens, European Committee for Standardization, Brussels, Belgium, 2005.

[38] D. C. Montgomery and G. C. Runger, Applied Statistics and Probability for Engineers, John Wiley \& Sons, Hoboken, NJ, USA, 5th edition, 2010. 


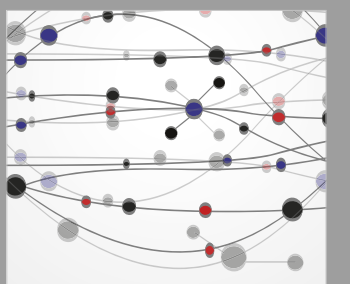

The Scientific World Journal
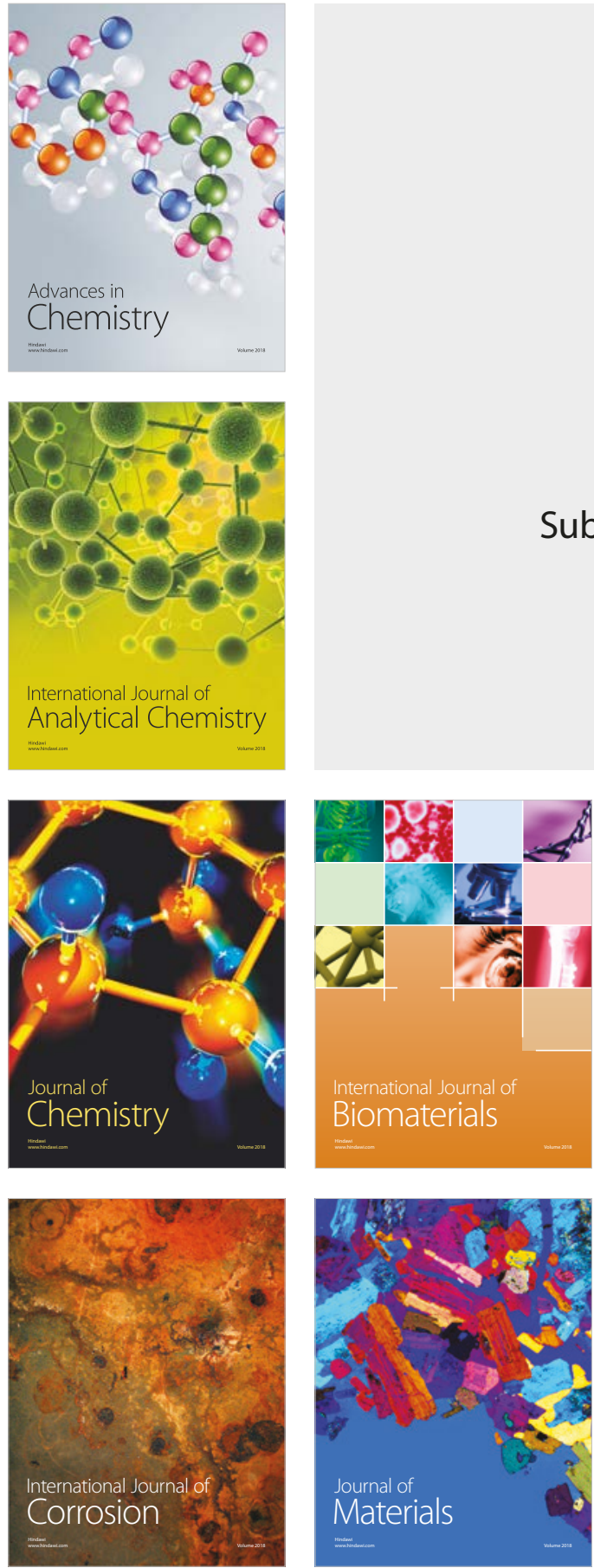

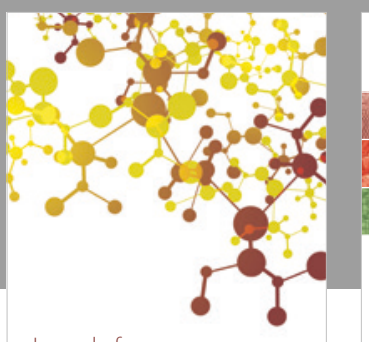

Journal of

Applied Chemistry
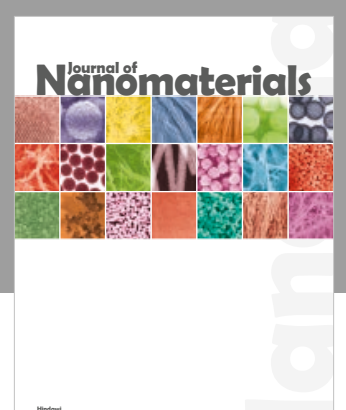

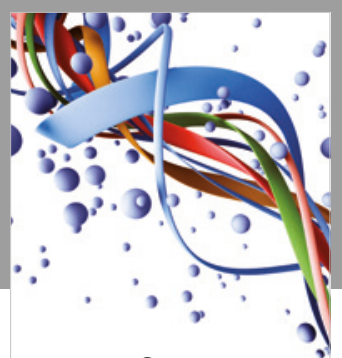

Scientifica

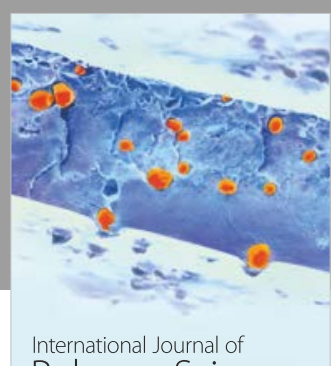

Polymer Science

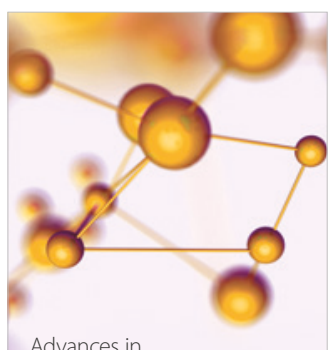

Physical Chemistry
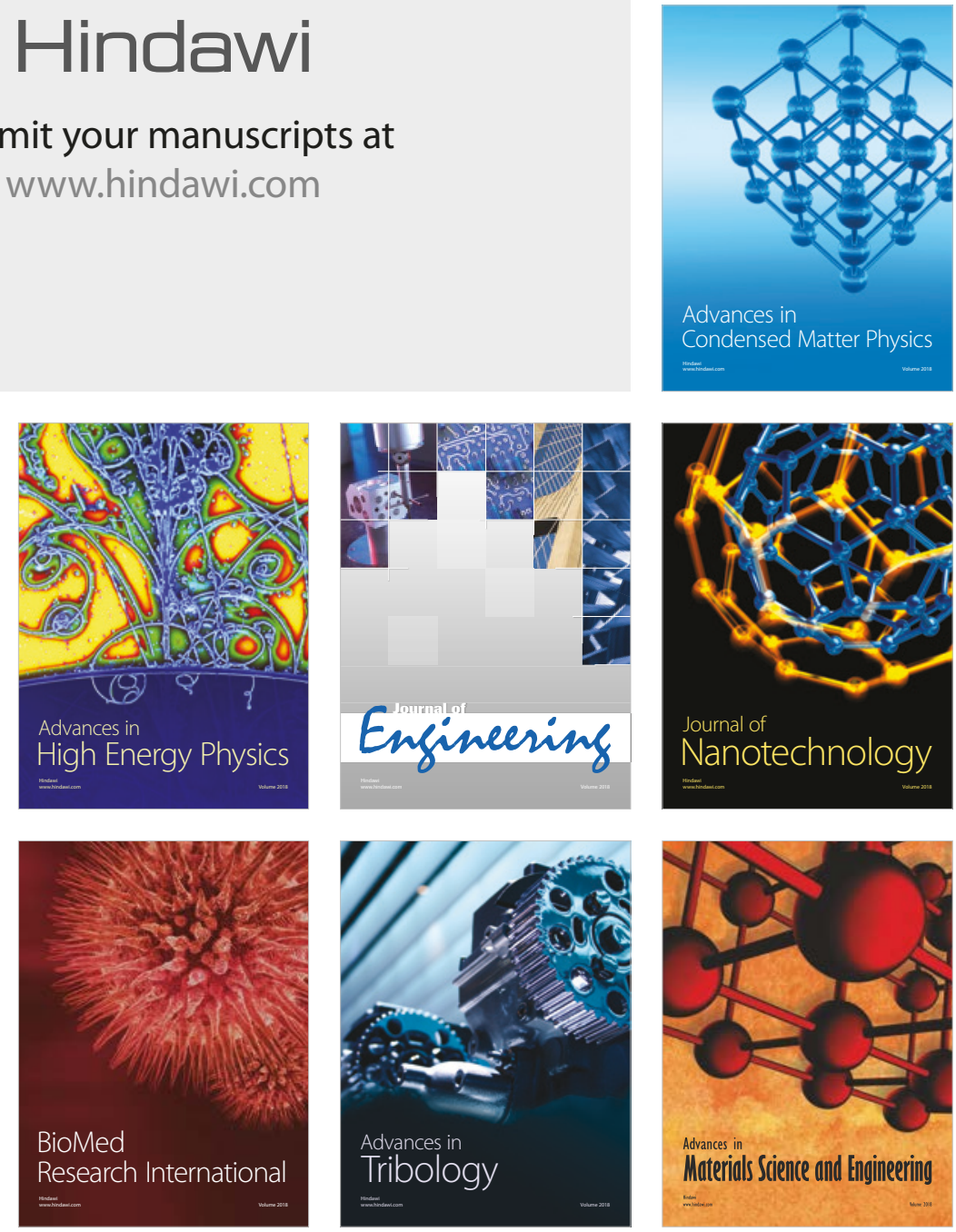